\title{
STUDY OF THE OXYGEN ELECTRODE REACTION USING MIXED CONDUCTING OXIDE SURFACE LAYERS. PART I: EXPERIMENTAL METHODS AND CURRENT-OVERVOLTAGE EXPERIMENTS
}

\author{
M.P. VAN DIJK *, K.J. DE VRIES \# and A.J. BURGGRAAF \\ Twente University of Technology, Department of Chemical Engineering. \\ Lahoratory for Inorganic Materials Science. \\ P.O. Box 217, 7500 AE Enschede, The Netherlands
}

Received 23 December 1985; accepted for publication 6 March 1986

The oxygen gas electrode has been studied for a number of mixed conducting oxide surface layers on top of $\mathrm{Gd}_{2} \mathrm{Zr}_{2} \mathrm{O}_{7}$ (TGZO) solid electrolytes. In part II of this paper we present the results of frequency dispersion measurements for the electrode reaction, supplying additional information to the results of current-overvoltage experiments presented in part $\mathrm{I}$. For both kinds of experiments the same trends were observed for the electrode polarization. Best results are obtained for a surface layer of TGZO, while p-type mixed conducting oxides give less decreased values of the electrode polarization. High electrode capacitances were found in the case of mixed conducting surface layers (about $700 \mathrm{~F} / \mathrm{m}^{2}$ ). The electrode reactions follow a Butier-Volmer type of equation. Most probabiy a diffusion process is rate controlling the overall charge transfer process.

\section{INTRODUCTION}

Solid state electrochemical cells based on oxygen ion conducting solid electrolytes involve electrode materials which promote the oxygen exchange reaction:

$$
1 / 2 \mathrm{O}_{2}+2 \mathrm{e}^{\prime}+\mathrm{v}_{\dot{0}} \neq 0_{0}^{\mathrm{x}}
$$

It has been pointed out in the literature that both the choice of the electrode material and its morphology, and the nature of the solid electrolyte phase near the electrode interface are Important factors in the performance of reaction $[1],(1-7)$. In summary, in the temperature range $500-800^{\circ} \mathrm{C}$, the influence of the solid electrolyte phase on the electrode reaction seems to be small. Pt and Ag turn out to be the better electrode metals, because of their high adsorptive capacity for oxygen. In the higher temperature range $\left(>800^{\circ} \mathrm{C}\right)$ the difference between the noble metals becomes less important and the properties of the electrolyte phase at the metal-electrolyte interface domi-

* present adress: Koninklijke Shell Laboratori um Amsterdam, P.0.Box 3003, 1003 AA Amsterdam. The Netherlands

\# to whom correspondence is to be sent nate the reaction performance. Schouler, for instance, noticed the influence of the number of oxygen ion vacancies at the electrolyte surface and the relation between the activation enthalpy of the electrode resistance and the activation enthalpy of oxygen ion vacancy migration in the bulk (1). Olmer and I saacs reported that $P t$ point electrodes contaminated with $\mathrm{Pr}$ showed higher current densities than the corresponding clean $\mathrm{Pt}$ electrodes. $\mathrm{BI}_{2} \mathrm{O}_{3}$ contamination was found to have a disadvantageous influence (4). On the other hand winnubst et al. found that $\mathrm{BI}_{2} \mathrm{O}_{3}$ doped yttria stabilized zirconia showed smaller electrode resistances than the corresponding $\mathrm{Bi}_{2} \mathrm{O}_{3}$-free solid electrolytes ( 6$)$. Current blackening, introducing electronic defects in the outmost surface layer of the solid electrolyte, leads to higher current densities at corresponding overpotentials $(2,7)$. Evidence for an electrolyte influence on the electrode reaction at temperatures below $800^{\circ} \mathrm{C}$ was found by Verkerk et al.(5). Marked differences are reported for $\mathrm{ZrO}_{2}, \mathrm{CeO}_{2}$ and $\mathrm{Bi}_{2} \mathrm{O}_{3}$ based solid electrolytes, resulting in either charge transfer or diffusion controlled electrode processes.

It is belleved that positive effects on the electrode reaction performance can be expected, when the surface layer of the solid elec-

0 167.2738/86/\$ 03.50 @ Elsevier Science Publishers B.V.

(North-Holland Physics Publishing Division) 


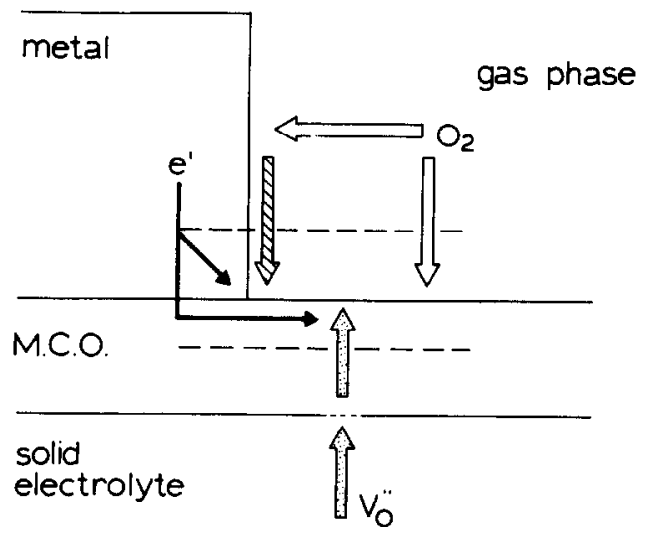

Fig.1. Mixed conducting oxide surface layer, supporting the performance of a noble metal electrode.

trolyte phase can be made active with respect to adsorption of oxygen, surface diffusion of oxygen, electron transf er processes and dissolution of oxygen into the solid electrolyte phase. Probably this can be realized by applying oxidic surface layers that show mixed conductivity, i.e. both high ionic and electronic conductivity $(8-10)$. Preferentially the mixed conductivity is combined with an

improvement of the adsorptive capacity for the reactants. This is illustrated conceptually in Fig. 1.

If particular mixed conducting oxides possess the above mentioned properties to a sufficient extent and especially the electronic conductivity is high enough, it may be possible to replace the noble metal electrodes by mixed conducting oxides. This was realized already by Badwal ( 8 ) for urania-scandia solid solutions or mixtures of these solid solutions with finely dispersed platinum.

In the present study the electrode properties of mixed ( $p$-type) conducting surface layers on top of a solid electrolyte phase are investigated by means of electrochemical techniques. The solid electrolyte chosen is $\mathrm{Gd}_{2} \mathrm{Zr}_{2} \mathrm{O}_{7}$ ( $\mathrm{TGZO}$ ) and the oxides used for surface layers are $\mathrm{Tb}_{2} \mathrm{Zr}_{2} \mathrm{O}_{7+\mathrm{y}}(\mathrm{TGZ100})$ and $\mathrm{Ce}_{0.7} \mathrm{~Tb}_{0.3_{2-y}}(\mathrm{CT} 3 \mathrm{O})$. Electrical transport properties of these materials have been published before $(9,10)$. In Part I of this paper the experimental methods and results of current-overvoltage experiments are discussed. Part II deals with results of small signal A.C. experiments.

\section{EXPERIMENTAL METHODS}

2.1 Electrode surface layers: Preparation and characterization

Substrate discs of TGZ0 were cut with a diameter of $10 \mathrm{~mm}$ and a thickness of $1 \mathrm{~mm}$. These discs (relative density $>93 \%$ ) were ground $f$ lat using $1 \mu \mathrm{m} \mathrm{Al} \mathrm{O}_{3}$ polishing powder. They were cleaned ultrasonically in ethanol and heat treated at $800^{\circ} \mathrm{C}$ for 1 hour.

The layers of TGZ100 and CT30 were applied by radio frequent sputtering, using a LeyboldHeraeus $z-400$ sputtering apparatus. For comparison a layer of TGZO was sputtered onto a TGZO substrate too. For the sputtering procedure targets were prepared from the oxides to be sputtered. The sputtering procedure was carried out in an atmosphere of $82 \% \mathrm{Ar}$ and $18 \% \mathrm{O}_{2}$ at $0.6-0.8 \mathrm{~Pa}$ and $1000-1500 \mathrm{~V}$.

Surface layers thus obtained were given a heat treatment in air at $1100^{\circ} \mathrm{C}$ for 16 hours to realize good adherent structures of the oxides. The thickness of the layers was determined from the step-change at the borders of simultaneously sputtered layers on partially covered glass plates, using a Zeiss Talysurf apparatus. It was found that the layer thickness increased linearly with the sputtering time at fixed conditions. Thicknesses of the surface layers used in the experiments are: TGZO: 600nm; CT30: 150 and $600 \mathrm{~nm}$; TGZ100: 150nm.

The composition of the sputtered layers was determined by $X$-ray fluorescence analysis, using a Philips PW 1410 spectrometer. For these experiments the sputtered layers on the glass plates were used. The relative deviation of the composition of the sputtered layers was always less than $1 \%$ from the composition of the target materials. Hence no preferential atomic sputtering rates were observed for the present materials and under the preparation conditions used.

The crystal, structure of the sputtered layers was examined with X-ray diffraction analysis, using a Philips PW 1330 powder-diffractometer and $\mathrm{Cu}-\mathrm{K} \alpha$ radiation. Taken before the final heat treatment at $1100^{\circ} \mathrm{C}$, the diffraction patterns of the sputtered layers showed rather broad peaks and a high background. Nevertheless the fluorite structure was observed already for all compositions, which implies that the oxides have been formed during sputtering. After the heat treatment the peaks were much sharper, almost as sharp as the diffraction peaks of the bare ceramic material are.

From the relative intensities of diffraction peaks, it turns out that preferential orientation occurs during the sputtering process. For the sputtered layers, it is seen that 
the (200) and (400) peaks are relatively intense and the (111) and (222) peaks are relatively faint or even absent. These results imply that $\{100\}$ crystal faces are exposed to the specimen surface predominantly, which may be of great importance for the adsorption properties of the surface. It can not be deduced from the diffraction patterns whether pyrochlore order is present for the TGZO sputtered layer. Since the sputtering process is very reactive and crystal growth has occurred after the heat treatment at $1100^{\circ} \mathrm{C}$, it is plausible. however, that cation diffusion or reconstructive (diffusionless) displacements have been large enough to result in (locally) ordered regions.

The microstructure of the sputtered layers was examined by means of a Jeol JSM 35CF electron microscope. It was found that homogeneous surface layers are obtained, with scattered holes, probably on places where the substrate material was porous too. The overall porosity of the sputtered layer seems to be small. For CT 30 and TGZ100 layers crushed parts are sometimes seen, probably due to the variations in oxygen stoichiometry of these materials,during heating and cooling procedures.

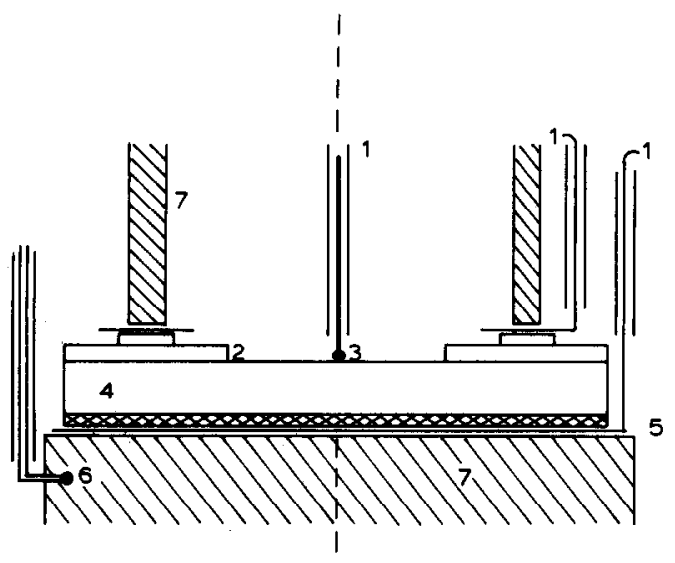

Fig.2. Schematic drawing of the measurement cell; cylindrical symmetry

1 Pt leads

2 working electrode: sputtered layer in contact with Au or Pt strip and Pt foil

3 reference electrode: Pt-point

4 solid electrolyte

5 counter electrode: porous sputtered Pt electrode, $\mathrm{Pt}$ foll

6 thermocouple

$7 \mathrm{Al}_{2} \mathrm{O}_{3}$-sample holder parts

\subsection{Electrical characterization}

The performance of the mixed conducting oxide surface layers in the electrochemical oxygen exchange reaction was examined by measuring current-overvoltage $(i-n)$ relations and impedance spectroscopy under small signal conditions. For these measurements a three electrode cell was used, schematically drawn in Fig 2.

The working electrode consists of an annular sputtered layer of the oxide and a gold or platinum ring. The inner diameter of the sputtered layer is $5 \mathrm{~mm}$, the outer diameter $10 \mathrm{~mm}$. The gold or platinum ring was prepared from wire of $0.5 \mathrm{~mm}$ diameter and was partially rlattened. The flattening resulted in an annular strip with outer diameter $8.5 \mathrm{~mm}$, width $0.6( \pm 0.1) \mathrm{mm}$ and thickness $0.3 \mathrm{~mm}$. Consequently the superficial geometrical contact area between the strip and the sputtered layer was $15( \pm 3) \mathrm{mm}^{2}$. This configuration was chosen not to obtain maximum current density for the working electrode, but in order to have a system in which specimens can be readily changed, where the contact between the strip and the sputtered layer is quite reproducible, and which has a good exposure to the gasphase. Gold has a low activity for oxygen adsorption compared to $\mathrm{Pt}$. Differences in the behaviour of sputtered layers with different compositions are supposed to be observed better with the Au-strip.

The strip was pressed onto the sputtered layer, using the $f$ ixed spring force of the measurement cell. A Pt-foll is put in between the strip and the sample holder, to provide contact with the Pt-lead to the outside of the cell. The strip was periodically replaced to prevent contamination, for instance due to alloying with platinum from the foil (in case of an Au-strip). It was checked that repeated measurements before and after the replacement of the gold strip gave simflar results.

The counter electrode consists of a $220 \mathrm{~nm}$ thick sputtered platinum electrode, which was made porous by heat treatment at $950^{\circ} \mathrm{C}$ for 1.5 hour. Stabilization occurs in the measurement cell by annealing the system at a temperature above the highest measurement temperature for two days. This electrode is put in contact with a Pt-foil. The reference electrode consists of a platinum point contact that can be pressed onto the specimen using a separate spring system, in the centre of the annular sputtered layer. This construction excludes thermovoltaic effects of the gold and platinum contacts, as was checked by measuring the electrode potentials at zero current.

The current-overvol tage $(1-n)$ measurements were carried out potentiostatically using a Solartron 1186 Electrochemical Interface (E.C.I.). The value of the potential between 
the reference and the working electrode was set at the external input of the E.C.I., using a function generator. This potential was varied linearly with a constant rate of $4 \mathrm{mV} / \mathrm{s}$. The potent1al drop between the reference and workIng electrode is equal to the sum of the overvoltage for the electrochemical reaction $(n)$, the polarization within the sputtered layer, the polarization at the interface sputtered layer-solid electrolyte and a certain polarization contribution $V^{*}$ of the solid electrolyte. $V^{*}$ is due to the fact that the potential of the oxygen ions in the solid electrolyte just below the sputtered layer differs from the potential of the oxygen $i$ ons at the reference electrode, since bending of the equipotential planes in the solid electrolyte between the working and the counter electrode occurs. The contact potential between the solid electrolyte and the reference electrode is neglegible, since no current flows across this interface. The total ohmic polarization of the sputtered layer, the sputtered layer-solid electrolyte interface and $V^{*}$ can be determined by a frequency dispersion analysis. This was done by supplying the output signal of a Solartron 1174 Frequency Response Analyzer (FRA) to the external input of the E.C.I., using a $10 \mathrm{mV}$ (rms) signal. The response of the cell was analyzed in terms of complex impedances using the combination of the FRA and a HP85 personal computer. The high frequency intercept with the real axis in the impedance plots, was found to be independent of $\mathrm{P}_{\mathrm{O}_{2}}$ and bias conditions. Hence this high frequency Impedance was interpreted as the ohmic polarization of the sputtered layer, the sputtered layer-solid electrolyte interface and $V^{*}$. Using the real part correction mode of the E.C.I. and the value of the ohmic polarization determined by frequency dispersion analysis, pure values of 1 and $n$ are obtained at the output connectors of the E.C.I. These output signals were $f$ ed into an $X-Y$ recorder to obtain graphs of the $1-n$ relations.

In the appendix to part $I$ of this paper it is made plausible that the contribution of $V^{*}$ to the total ohmic polarization loss between the reference and the working electrode is largest. It is explained in which way the results of the various experiments are scaled to each other, the essential feature being that the results are recalculated for equal contact area between the noble metal strip and electrode surface.

Extending the frequency dispersion impedance measurements to the I ow frequency $r$ ange (down to $1 \mathrm{mHz}$ ) with zero bias, the polarization of the electrode reaction under small signal conditions is obtained (see part II). The advantage of this working procedure is that the sample and the measurement conditions (temperature, atmosphere) are the same for $1-n$ and frequency dispersion experiments, supplying complementary information on the electrochemical process.

With the procedure outlined here $1-\eta$ curves and impedance diagrams were recorded for a varlety of oxygen partial pressures $\left(4 \times 10^{-5}-0.6 \mathrm{~atm}\right)$ at a fixed temperature $\left(727 \pm 3^{\circ} \mathrm{C}\right)$ and subsequently for a set of temperatures $\left(580-727^{\circ} \mathrm{C}\right)$ at $\mathrm{P}_{2}-0.21 \mathrm{~atm}$. The varying oxygen partial pressure was realized by mixtures of $\mathrm{N}_{2}$ and $\mathrm{O}_{2}$ and was monitored using an oxygen gas sensor.

\section{RESULTS.}

\subsection{Current-overvol tage relations}

Figs. 3a-c show the results for the various electrode configurations with a Au strip. Evidently for all configurations and $f$ or all $\mathrm{P}_{\mathrm{O}_{2}}$ and temperatures of the measurements, the $1-\eta$ curves are asymmetrical, resulting in much larger anodic than cathodic current densities at corresponding overvoltage values. The samples with a sputtered layer on top of the solid electrolyte, show less electrode polarization in comparison to the bare ceramic solld electrolyte sample. Among these sputtered layers, surprisingly, the configuration with the lonic conduct or TGZO performs best, followed by CT30 and TGZ100. A preliminary conclusion is that the presence and nature of a sputtered layer on top of a solid electrolyte is of great importance. Mixed, p-type, conductivity does not lead, however, to increased current densities, but on the contrary, has a negative influence compared to the ionically conducting sputtered layer. In the presently considered temperature range the nature of the solid electrolyte phase actually influences the electrode reaction perf ormance.

The $1-n$ relations are very sensitive to $\mathrm{P}_{2}$ variations. This can be seen by comparing curves for the same configuration in Fig. 3a to 3c. Especially at $\mathrm{P}_{\mathrm{O}_{2}}<10^{-3}$ atm cathodic current densities are very small compared to anodic current densities at the same overvoltages. This is discussed in terms of a $11 \mathrm{miting}$ current below.

In Fig. 4 resul ts are compared for a $150 \mathrm{~nm}$ and a $600 \mathrm{~nm}$ sputtered layer of CT 30 . The layer thickness has no influence on the current density at corresponding potentials, except for large cathodic potentials, where the thinner layer gives rise to higher currents at the same overvoltages. This seems to arise from a larger 

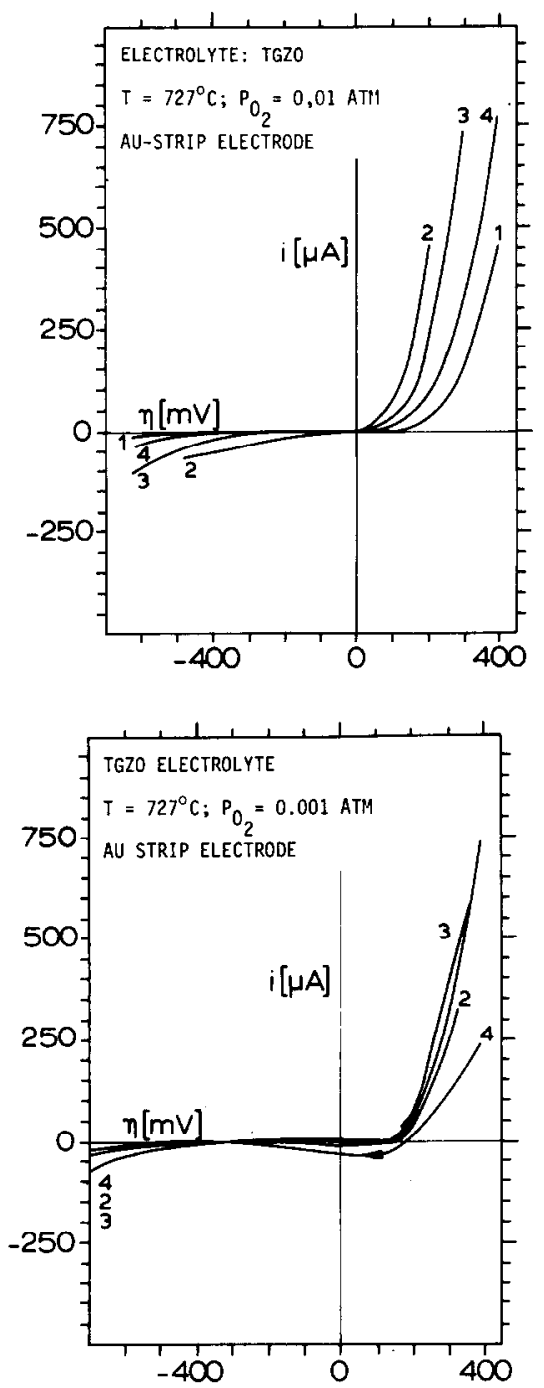

cathodic limiting current in the case of the thinner I ayer.

Fig. 5 shows the effect of the nature of the noble metal on the electrode reaction for a $600 \mathrm{~nm}$ sputtered layer of CT30. Obviously the Pt-strip leads to higher current densities at corresponding $n$-values than the Au-strip. This holds both for the cathodic and anodic reaction, but is more pronounced for the cathodic region. This is discussed in terms of charge transfer coefficients below.

Cathodically the curves for Pt-strips show a large hysteresis, which was more pronounced for

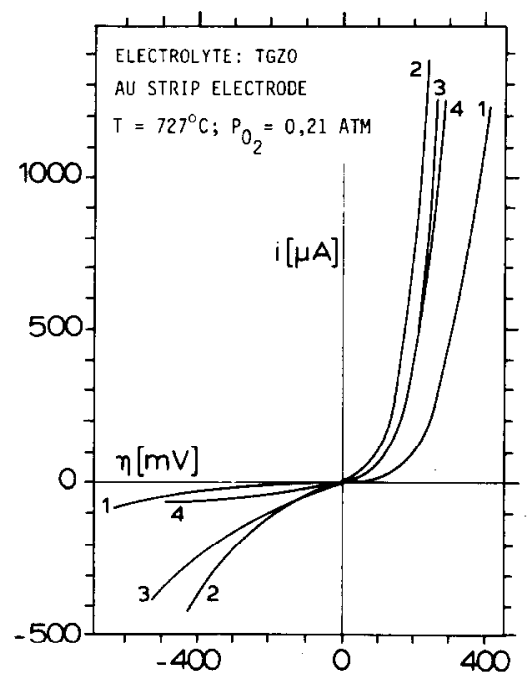

Figs. 3a-3c. Current-overvoltage results for various electrode configurations at three different $P_{O_{2}}$-values.

$\begin{array}{ll}\text { 1: bare TGZO } & \text { 2: } 600 \mathrm{~nm} \text { TGZO } \\ \text { 3: } 600 \mathrm{~nm} \mathrm{CT30} & \text { 4: } 150 \mathrm{~nm} \text { TGZ100 }\end{array}$

CT30 layers than for TGZO layers.

Using the Au-strip a hysteresis occurs in the $i-n$ curves around the origin, especially in the case of the mixed conducting oxides CT30 and TGZ100. It is less pronounced for the bare electrolyte and for the sputtered layer of TGZO. The width of the hysteresis loop increases when the rate of potential variation between the reference and the working electrode is increased, which 1 mplies that the hysteresis is connected with an out of equilibrium situation for the electrode reaction. Thus the relaxation time for the electrode process in the case of a 


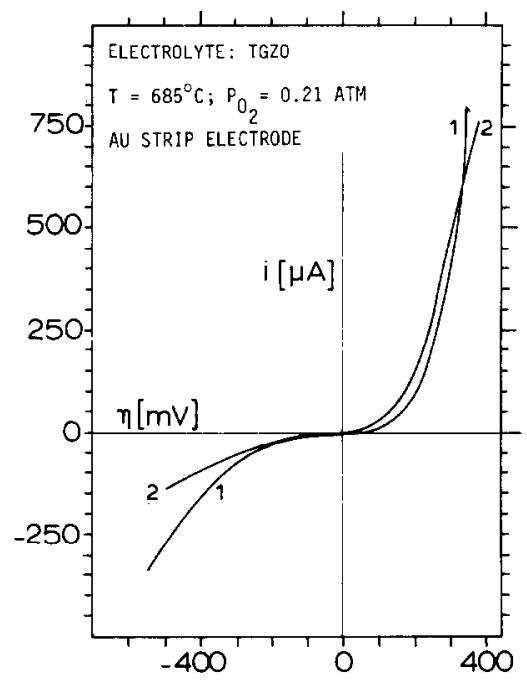

Fig.4. Comparison of current-overvoltage curves for 1: 150nm CT30, 2: 600nm CT30.

mixed conducting oxide surface layer is longer than for a purely ionic conducting surface layer. This is similarly observed in the impedance plots (see part II).

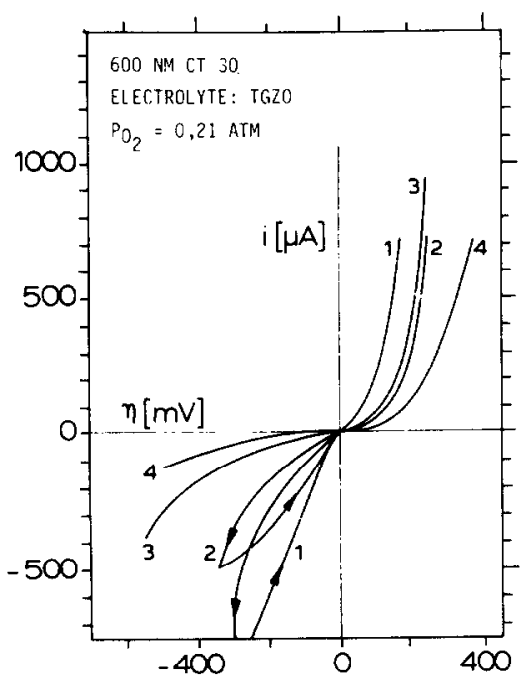

Fig.5. Comparison of $i-n$ curves for different noble metal strip contacts.
1: Pt, $728^{\circ} \mathrm{C}$
2: Pt, $684^{\circ} \mathrm{C}$
3: $\mathrm{Au}, 728^{\circ} \mathrm{C}$
4: Au, $684^{\circ} \mathrm{C}$

The $1-n$ curves can be analyzed according to the well known Butler-Volmer equations (11). In the case of pure charge transfer limited electrochemical reactions, $i$ and $n$ are related by:

$$
i=i_{0}\left[\exp \left(a_{a} n^{*}\right)-\exp \left(-\alpha_{c} n^{*}\right)\right]
$$

A modified Butler-Volmer equation incorporating effects of mass transport Iimitation at the electrodes is given by:

$$
i=\frac{\exp \left(\alpha_{\left.a^{n^{*}}\right)}-\exp \left(-\alpha_{c} n^{*}\right)\right.}{1_{0}^{-1}+i_{1}^{-1} \exp \left(\alpha_{a} n^{*}\right)+i_{1}^{-1} \exp \left(-\alpha_{c} n^{*}\right)}
$$

which in case $i_{1 c}$ is small compared to $i_{0}\left(1_{1}^{-1}=0\right)$ results in:

$$
i=i_{1 c}\left[\exp \left\{\left(a_{a}+\alpha_{c}\right) n^{*}\right\}-1\right]
$$

In these equations $\alpha_{a}$ and $\alpha_{c}$ are the anodic and cathodic charge transfer coefficients, io is the exchange current at zero overvoltage, $i_{1}$ and $i_{1 c}$ are the mass transport limiting currents for the anodic and cathodic reaction and $n *=\mathrm{nFn} / \mathrm{RT}$.

Using plots of $\ln (i)$ versus $n$, the charge transfer coefficients can be determined from the slopes of the linear parts in the plots (Tafel behaviour), as 1llustrated in Fig. 6 . Extrapolation of the 1 inear parts gives the exchange current 1 at the intercept with the current axis. It is noticed that, when diffusion limitation contributes to the experimental behaviour, the values of the charge transfer coefficients and exchange current, obtained from $T$ afel plots, consequently, are not equal to the true Faradaic values, and will be indicated as the apparent parameters $\alpha_{a}{ }^{*}, \alpha_{c}{ }^{*}$ and

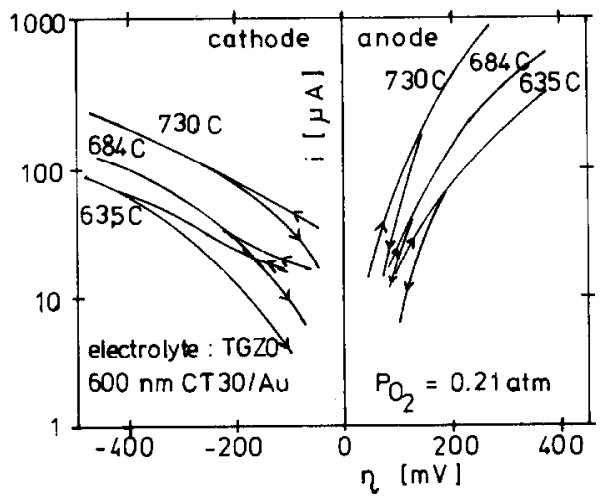

Fig.6. Representative Tafel plots, showing the linear behaviour for not too large $n$-values. 


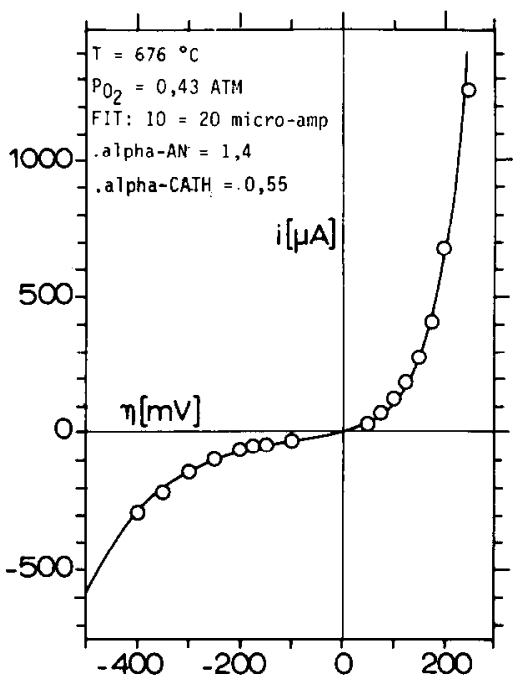

Fig.7. Example of a current-overvoltage curve, calculated with the parameters derived from a Tafel plot. The experimental data points are shown.

10*. This will be dealt with in the discussion part. As an example a representative calculated current-overvoltage curve, using parameters fram the analysis of a Tafel plot, is shown in F1g. 7, together with the experimental data points.

In Table I the apparent charge transfer coefficients are given as determined from the

TABLE I.

Charge transfer coefficients as determined from Tafel plots for the various electrode configurations. In the columns for $\alpha_{a}^{*}$ and $\alpha_{c}^{*}$ the first number is for the lower temperatures, the second for the higher temperatures.

\begin{tabular}{|c|c|c|c|c|c|}
\hline $\begin{array}{l}\text { electrode } \\
\text { conf } 18 .\end{array}$ & strip & & $a^{*}$ & $\begin{array}{c}a_{c}{ }^{*} \\
( \pm 0.2)\end{array}$ & $\begin{array}{l}{ }^{\mathrm{P}_{2}} \\
(\operatorname{atm})\end{array}$ \\
\hline bare TGZO & $\mathrm{Au}$ & & 1.6 & 0.35 & 0.21 \\
\hline $600 \mathrm{~nm}$ TGZO & $\mathrm{Au}$ & 1.4 & 1.7 & 0.8 & 0.01 \\
\hline$"$ & $\mathrm{Au}$ & 1.1 & 1.6 & $0.7 \quad 0.6$ & 0.21 \\
\hline$"$ & $\mathrm{Au}$ & & 1.5 & 0.6 & 0.43 \\
\hline$"$ & Pt & 1. & 1 & 0.7 & 0.21 \\
\hline $\begin{array}{l}150 \mathrm{~nm} \text { CT30 } \\
600 \mathrm{~nm} \text { CT30 }\end{array}$ & $\begin{array}{l}\mathrm{Au} \\
\mathrm{Au}\end{array}$ & $\begin{array}{l}1.25 \\
1.3\end{array}$ & $\begin{array}{l}1.55 \\
1.5\end{array}$ & $\begin{array}{ll}0.6 & 0.5 \\
0.7 & 0.4\end{array}$ & $\begin{array}{l}0.21 \\
0.21\end{array}$ \\
\hline & Pt & 1. & 1 & 0.7 & 0.21 \\
\hline $150 \mathrm{~nm}$ TGZ100 & $\mathrm{Au}$ & 1.2 & 1.5 & 0.4 & 0.21 \\
\hline
\end{tabular}

Tafel plots for different values of $\mathrm{P}_{\mathrm{O}_{2}}$. It appears that the sum of $\alpha_{a}{ }^{*}$ and $\alpha_{c}{ }^{*} 1 s^{2}$ always close to 2.0. Using the Au-strip electrode and at $\mathrm{P}_{\mathrm{O}_{2}} \geq 0.01 \mathrm{~atm} \alpha_{\mathrm{a}}{ }^{*}$ is generally close to 1.5 at the higher temperatures and decreases to a slightly lower value at the lower temperatures. The value of $\alpha^{*}$ is close to 0.5 at the higher temperatures. At the lower temperatures it is slightly larger, but for larger cathodic potentials approaches 0.5 again (see Fig. 6). At $\mathrm{P}_{\mathrm{O}_{2}}<0.01 \mathrm{~atm} \alpha_{a}{ }^{*}$ approaches the value 2.0 and cathodically no slope can be determined. Generally the determination of the slopes is hindered by the effects of hysteresis.

In F1g. 6 it is seen that the $1-n$ curves tend to limiting currents at larger cathodic and anodic potentials, but the anodic limiting currents are many times larger than the cathodic limiting currents.

Apparent charge transfer coefficients for the electrode configurations with the Pt-strip deviate from the corresponding ones for the configurations with the Au-strip. In most cases the cathodic coefficient $\mathrm{f}$ or $\mathrm{Pt}$ is somewhat larger and the anodic coefficient is somewhat smaller.

Instead of analyzing $1_{0}$-values obtained fram the Tafel plots, the electrode reaction at small overpotentials is characterized by the electrode resistance as determined from the frequency dispersion impedance measurements. In our opinion the latter procedure reveals more accurate and also additional information.

The results of these experiments are dealt with in part II. The discussion of the current-overvoltage measurements is also postponed to part II, since the information from the frequency dispersion experiments is used too in modeling the experimental results for the oxygen gas electrode reaction.

\section{CONCLUSIONS}

Some preliminary conclusions can be drawn already from the experimental section and current-overvol tage results presented.

1. Surface layers of mixed oxides, ranging from $50 \mathrm{~nm}$ to at least a few microns, on ceramic substrates can be obtained by radio frequent sputtering of the desired compositions. Preferential orientation during the crystallization process in the surface layer occurs.

2. The application of sputtered layers on a solid electrolyte phase improves the oxygen electrode react 1 on by one order of magnitude compared to a bare solid electrolyte phase and a Au strip electrode. The largest im- 
provement was found for sputtered layers of the ion conducting oxide TGzo. At a cathodic potential of $500 \mathrm{mV}$ the current density for the sputtered layer is 11 times higher than for the bare specimen. Hence the electrolyte surface morphology plays an important role in the performance of the electrode reaction.

3. A somewhat smaller Improvement was found for a CT30 sputtered layer, while the application of a TGZ100 sputtered layer has only minor positive effects, compared to the bare solid electrolyte sample. Hence, p-type (electron-hole) conductivity does not increase the electrode polarization compared to the sputtered layer of TGZO.

\section{ACKNOWLEDGEMENT}

Mr. H. Kruldhof and Mr. B. van Dongen are acknowledged $f$ or their experimental assistance. This investigation was supported by the Netherlands Foundation for Chemical Research (SON) with the financial aid from the Netherlands Organization for the Advancement of Pure Research ( $\mathrm{ZWO}$ ).

\section{APPENDIX}

In Fig.1-app the ohmic polarization values have been plotted as a function of temperature for the different sputtered layers and for a bare specimen. No systematic influence of the sputtered layer thickness is observed. Moreover repeated measurements on the same electrode configuration after dismantling the cell revealed a spread in results similar to the spread in Fig.1-app for different configurations. The activation enthalpy for the observed straight lines is in the range $85-100 \mathrm{~kJ} / \mathrm{mol}$, which corresponds to the activation enthalpy for ionic conductivity of the TGZO solid electrolyte (9). The linearity of these curves together with the value of the activation enthalpy makes it plausible that the ohmlc polarization is mainly controlled by $V^{*}$. The value of $V^{*}$ may be influenced by the position of the reference electrode in the centre of the working electrode.

The difference in absolute values for the various electrode configurations and for repeated measurements of the same configurations are supposed to arise from the effective contact of the gold and platinum strip with the sputtered layer or bare electrolyte and from the exact position of the reference electrode. This 1 mmediately implies that the mixed conducting oxide layers are not active over all their surface area, but that the active area is re-

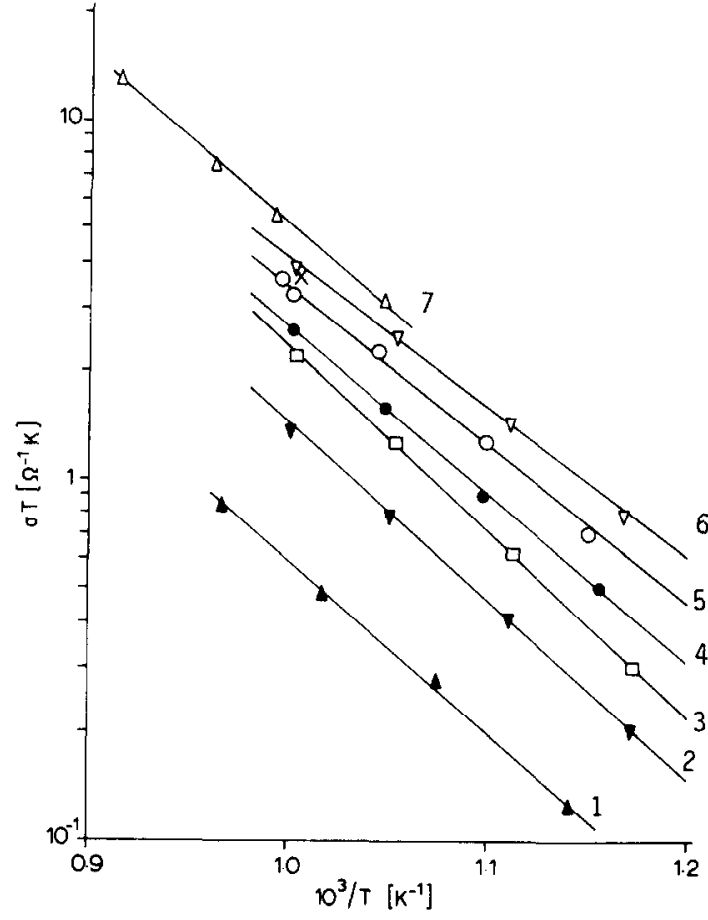

Fig. 1-app. Ohmic polarization versus temperature. (at $\mathrm{P}_{\mathrm{O}_{2}}=0.21 \mathrm{~atm}$ ).

$1600 \mathrm{~m} \mathrm{TGZ0} / \mathrm{Pt}$

$2600 \mathrm{~nm} \mathrm{TGZO/Au}(0.01 \mathrm{~atm})$

$3600 \mathrm{~nm}$ TGZO/AU

$4600 \mathrm{~nm} \mathrm{CT30/Pt}$

$5600 \mathrm{~nm} \mathrm{CT30/Au}$

$6150 \mathrm{~nm} \mathrm{TGZ100/ \textrm {Au }}$

$7 \quad 150 \mathrm{~nm} \mathrm{CT3O/AU}$

stricted to regions close to the noble metal strip contact.

In order to compare results of electrical measurements for the different electrode configurations, these results have to be scaled for the same contact area between the noble metal strip and the surface layer. For this purpose an ohmic polarization value of $500 \Omega$ at $1000 \mathrm{~K}$ was taken as the reference. An activation enthalpy of $90 \mathrm{~kJ} / \mathrm{mol}$ was used to calculate scaling factors at other temperatures. In 1 18.2-app.a the incorrected data are presented at $\mathrm{P}_{\mathrm{O}_{2}}=0.21$ atm and at $\mathrm{T}=680^{\circ} \mathrm{C}$. In F1g.2-app.b the same data are presented as in F1g.2-app.a, but now scaled to a fixed contribution of ohmic polarization, according to the procedure outlined above. It can be seen that this scaling operation has influence on the 

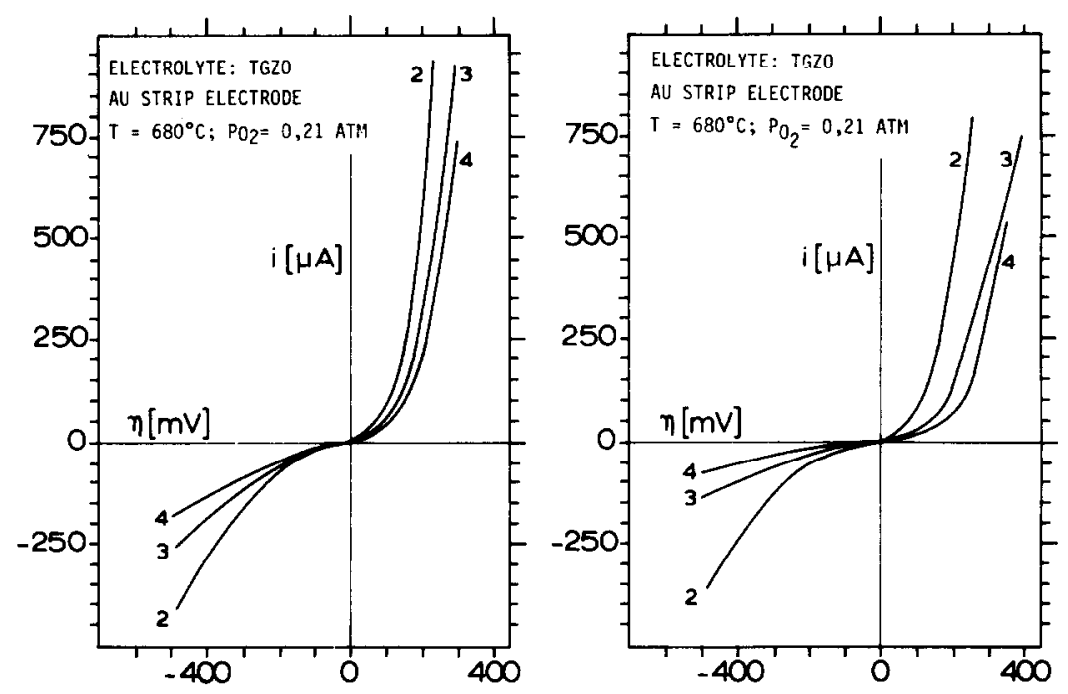

Fig. 2-app.a. Uncorrected experimental current-overvoltage relations. $\begin{array}{lll}\text { 2: } 600 \mathrm{~nm} \mathrm{TGZO} & \text { 3: } 600 \mathrm{~nm} \text { CT30 4: } 150 \mathrm{~nm} \text { TGZ100 }\end{array}$

b. Same experimental data as in 2-app.a. but scaled to a fixed contribution of ohmic polarization.

2: $600 \mathrm{~nm}$ TGZO 3: 600 na CT30 4: 150 $\mathrm{nm}$ TGZ100

relative positions of the various $1-\eta$ curves, but trends remain unchanged. In all other $\mathrm{fig}-$ ures measurement data have been scaled.

\section{REFERENCES}

(1) E.J.L. Schouler, Solid State Ionics $9 / 10$ (1983) 945.

(2) R.J. Brook, W.L. Pelzman, F.A. Kröger, J. Electrochem.Soc. 118 (1971) 185.

(3) D.Y. Wang, A.S. Nowl ck, J.Electrochem.Soc. 126 (1979) 1155, ibldem 126 (1979) 1166 and 128 (1981) 55 .

(4) L.J. Olmer, H.S. Isaacs, J.Electrochem. Soc. 129 (1982) 345 and H.S. Isaacs, L.J. Olmer, ibidem 129 (1982) 436.

(5) M.J. Verkerk, M.W.J. Hammink, A.J. Burggraaf, J.Electrochem.Soc. 130 (1983) 70 and M.J. Verkerk, A.J. Burggraaf, ibidem 130 (1983) 78 .
(6) A.J.A. Winnubst, A.H.A. Scharenborg, A.J. Burggraaf, Solid State Ionics 14 (1984) 319.

(7) B.C. Nguyen, D.M. Mason, L.M. RinconRubio, submitted to J.Electrochem.Soc.

(8) S.P.S. Badwal, J.Electroanal .Chem. 161 (1984) 75 .

(9) M.P. van Dijk, K.J. de Vries and A.J. Burggraaf, Solid State Ionics 16 (1985) 211.

(10) M.P. van Dijk, Ph. D. Thesis, Twente University of Technology, Enschede, The Netherlands (1985).

(11) J.0.M. Bockris, K.N. Reddy, in: Modern Electrochemistry, Vol.2 (Pienum Press, New York, 1973). 